\title{
Overexpression of the GmGAL2 Gene Accelerates Flowering in Arabidopsis
}

\author{
Jiaohui Xu • Xiaofang Zhong • Qingzhu Zhang • \\ Hongyu Li
}

Published online: 30 March 2010

(C) The Author(s) 2010. This article is published with open access at Springerlink.com

\begin{abstract}
A soybean MADS box gene GmGAL2 (Glycine max AGAMOUS Like 2), a homolog of AGL11/STK, was investigated in transgenic Arabidopsis lines. Ectopic expression of GmGAL2 in Arabidopsis enhanced flowering, under both long-day and short-day conditions, by promoting expression of key flowering genes, CONSTANS $(C O)$ and FLOWERING LOCUS T $(F T)$, and lowering expression of floral inhibiter FLOWERING LOCUS C (FLC). Moreover, frequency of silique pod set was also lower in transgenic compared to control Arabidopsis plants. RT-PCR results revealed that $\mathrm{GmGAL2}$ was primarily expressed in the flowers and pods of soybean plants, GmGAL2 expressed higher in SD than LD in soybean.
\end{abstract}

Keywords Soybean (Glycine max [L.] Merr.) · GmGAL2 . MADS box Flowering

\section{Introduction}

MADS box genes are found in both plants and animals and encode transcription factors that contain a highly conserved DNA-binding domain, which can regulate reproductive and vegetative developments (Alvarez-Buylla et al. 2000). In Arabidopsis thaliana, the MADS box gene family comprises

J. Xu $\cdot$ X. Zhong $\cdot$ Q. Zhang $\cdot$ H. Li $(\bowtie)$

Institute of Crop Science,

National Key Facility for Crop Gene Resources

and Genetic Improvement,

Chinese Academy of Agricultural Sciences,

Beijing 100081, China

e-mail: lihongyu@caas.net.cn more than 100 members, which can be grouped into five subfamilies, namely MIKC, Ma, Mb, Mg, and Md (Parenicova et al. 2003). The $\mathrm{K}$ box protein-protein interaction domain in MADS box proteins mediates the heterodimerization of MIKC-type MADS proteins that is necessary for the protein's function. MADS box genes control the identity of the apex meristem and floral organs, and the development of shoot, leaf, root, flower, and fruit (De Bodt et al. 2003; Foo et al. 2006; Irish 2003; Kater et al. 2006; Messenguy and Dubois 2003; Rijpkema et al. 2007; Robles and Pelaz 2005; Saedler and Huijser 1993). In addition, the MADS box proteins also regulate flowering time. For example, SUPPRESSOR OF OVEREXPRESSION OF CONSTANS (SOCl) is an integrator of different flowering pathways and can promote flowering (Kim et al. 2001; Lee et al. 2004; Moon et al. 2003; Samach et al. 2000; Sheldon et al. 1999), whereas FLOWERING LOCUS C (FLC) acts as a repressor of flowering (Hepworth et al. 2002; Poduska et al. 2003; Rouse et al. 2002; Swarup et al. 1999). Some MADS box proteins have multiple functions. AP1, AGL24, and SVP act redundantly to control the identity of the floral meristem and to repress expression of class $\mathrm{B}, \mathrm{C}$, and $\mathrm{E}$ genes (Gregis et al. 2009). A MADS box gene AGL12 regulating root development and flowering was identified (Tapia-Lopez et al. 2008).

Seedstick/Agamous like 11 (STK/AGL11) is a key gene that controls ovule identity in Arabidopsis. In situ hybridizations revealed that $A G L 11$ RNA accumulated only in developing ovules and associated placental tissues; no AGL11 RNA was detected in other floral organs during earlier or later stages of flower development (Rounsley et al. 1995). Ectopic expression of the STK/AGL11 gene was sufficient to induce the transformation of sepals into 
carpeloid organs bearing ovules (Favaro et al. 2006; Pinyopich et al. 2003); it also resulted in the presence of curved rosette leaves and bracts, and the conversion of sepals into carpeloid organs that could develop mature ovules (Favaro et al. 2006). STK sequences are highly conserved among dicots and monocots; however, their functions are not always the same (Colombo et al. 1997; Lopez-Dee et al. 1999; Skipper et al. 2006). FBP11, an AGL11 homolog in petunia, regulates ovule development; ectopic expression of FBP11 induced the formation of ovules on the sepals and petals in petunia (Battaglia et al. 2006; Colombo et al. 1997, 1995). Ectopic expression of LIMADS2, an AGL11 homolog from lily (Lilium longiflorum), caused the conversion of sepals and petals to carpel- and stamen-like structures in transgenic Arabidopsis plants (Tzeng et al. 2003). Interestingly, heterologous, ectopic expression of AGL11 in Arabidopsis could not induce ectopic ovule formation. Ectopic expression of OSMADS13, an AGL11 homolog from rice, failed to induce ectopic ovule formation as did FBP11 in Arabidopsis (Favaro et al. 2006). These results indicate that AGL11 might function in a species-dependent mode. AGL11 also plays a role in flowering regulation. Overexpression of LIMADS2 caused early flowering in lily (Tzeng et al. 2003). Such pleiotropic phenotypes are widely present in the plant kingdom. The blue light receptor, Cryptochrome (CRY) 2, has been shown to be a regulator of flowering and growth of the hypocotyl (El-Din El-Assal et al. 2003; Guo et al. 1998), which also affects fruit length, ovule number per fruit, and percentage of unfertilized ovules (Guo et al. 1998).

The time to flower affects yield of soybean. As a shortday plant, flowering of soybean is sensitive to day length, which makes soybean an important model plant for photoperiod research (Zhang et al. 2008). We cloned and analyzed several MADS box genes from soybean by Rapid Amplification of cDNA ends (RACE). One of these soybean MADS box genes, GmGAL2 is a homolog of $A G L 11 / S T K$. We found that soybean GAL2 affects flowering time in Arabidopsis when overexpressed.

\section{Materials and Methods}

\section{Plant Growth}

Seeds of soybean (Glycine max L. "KN 18") were sown in pots (diameter, $18 \mathrm{~cm}$; height, $16 \mathrm{~cm}$ ) with mixed field soil, turf soil, and vermiculite (2:2:1). Soybean plants were grown in a chamber with a controlled environment in shortday conditions $\left(8 \mathrm{~h} / 16 \mathrm{~h}\right.$, light/dark; $\left.60 \mu \mathrm{mol} \mathrm{m}^{-2} \mathrm{~s}^{-1}\right)$ and long-day conditions $\left(16 \mathrm{~h} / 8 \mathrm{~h}\right.$, light/dark; $\left.60 \mu \mathrm{mol} \mathrm{m}^{-2} \mathrm{~s}^{-1}\right)$ at a constant $25-28^{\circ} \mathrm{C}$. Arabidopsis plants grew in long-day $(16 \mathrm{~h} / 8 \mathrm{~h}$, light/dark $)$ or short-day $(8 \mathrm{~h} / 16 \mathrm{~h} /$, light/dark $)$ conditions $\left(60 \mu \mathrm{mol} \mathrm{m}{ }^{-2} \mathrm{~s}^{-1}\right)$ at a constant $22^{\circ} \mathrm{C}$. Data were collected from more than 30 plants, and all experiments were repeated in triplicate.

\section{RNA Preparation and Gene Cloning}

For gene cloning RNA preparation, mixable shoot apical meristem of soybean on different stages (unifoliate, the first trifoliate, the second trifoliate, and the third trifoliate) were harvested in short-day conditions $(8 \mathrm{~h} / 16 \mathrm{~h}$, light/dark). Different soybean organs were sampled at different stages in short-day conditions ( $8 \mathrm{~h} / 16 \mathrm{~h}$, light/dark), for example when each new leaf (unifoliate or trifoliate) expanded fully, for GAL2 expression analysis. Ten-day-old Arabidopsis seedlings in long-day conditions $(16 \mathrm{~h} / 8 \mathrm{~h}$, light/dark, light was provided from 8:00 am to 24:00 pm everyday) were harvested at 11:00 am. Soybean flowers and immature pods were sampled in long-day conditions $(16 \mathrm{~h} / 8 \mathrm{~h}$, light/dark, light was provided from $8: 00$ am to $24: 00 \mathrm{pm}$ everyday) and short-day conditions $(8 \mathrm{~h} / 16 \mathrm{~h}$, light/dark, light was provided from 8:00 am to 16:00 pm everyday). RNA was prepared with Trizol (Invitrogen) and reversed transcribed to cDNA with M-MLV RT (Fermentas).

We detected a set of ESTs that showed high sequence similarity to AGL11 (The Gene Index Project, http://compbio. dfci.harvard.edu/tgi/). Among them, AW705451 covered the $5^{\prime}$ terminal sequence of a candidate gene. Based on the sequences of AW705451, specific primers for RACE of the full length of candidate gene were designed: forward primer GAL2-F1 and reverse primer GAL2-R1 (Table 1). The reverse primer contained part of the adapter primer that was employed as a primer for reverse transcription, leading to higher efficiency. The resultant clones were sequenced to confirm their sequences.

\section{RT-PCR and Quantitative PCR}

RT-PCR was performed with the primers shown in Table 1. Quantitative PCR was carried out by ABI StepOne according to the manufacturer's instructions (ABI). Total cDNA (100 ng per reaction) was used as the template for RT-PCR. PCR products were analyzed using $1.2 \%$ agarose gel electrophoresis. All experiments were replicated in triplicate. The expression level of the $G m U B Q$ gene was used as an internal control to normalize and calculate relative expression levels of genes tested using ImageJ software (http://rsb.info.nih.gov/ij/).

Constructing Expression Vectors and Plant Transformation

Construction of the expression vector was based on Gateway technology. The ORF of the GAL2 gene was cloned into Entry clone pDONR201 by BP clonase (Invitrogen) and 
Table 1 Primers employed in this study

\begin{tabular}{|c|c|c|}
\hline Reaction & Name of primers & Sequence $\left(5^{\prime}\right.$ to $\left.3^{\prime}\right)$ \\
\hline Reverse transcription & RTP & GACTCTGATGCTGACAATGACTTTTTTTTTTTTTTTTT \\
\hline \multirow[t]{2}{*}{ GAL2 cloning } & GAL2-F1 & TTCATTTCTTTGGATTAGAAATTTTTCC \\
\hline & GAL2-R1 & GACTCTGATGCTGACAATGACTTT \\
\hline \multirow[t]{2}{*}{ RT-PCR for GAL2 } & GAL2-F2 & TGATGCCTTAAGCACACTGACT \\
\hline & GAL2-R2 & TGAGTGAGGGTAAACAGTTCCAC \\
\hline \multirow[t]{2}{*}{ Quantitative PCR for GAL2 } & GAL2-37F & AACACAACAAATCGGCAAGTGA \\
\hline & GAL2-152R & CGGCTGGAGAAGACGATGAG \\
\hline \multirow[t]{2}{*}{ RT-PCR for AtCO } & $\mathrm{CO}-\mathrm{F}$ & CATTAACCATAACGCATACATTTCA \\
\hline & $\mathrm{CO}-\mathrm{R}$ & CTCCTCGGCTTCGATTTCTC \\
\hline \multirow[t]{2}{*}{ RT-PCR for AtFT } & FT-F & GAACAACCTTTGGCAATGAGA \\
\hline & FT-R & TCTTCCTCCGCAGCCACT \\
\hline \multirow[t]{2}{*}{ RT-PCR for AtSOC1 } & SOC1-F & CTAAACGTAAACTCTTGGGA \\
\hline & SOC1-R & CAGAACTTGGGCTACTCTCT \\
\hline \multirow[t]{2}{*}{ RT-PCR for AtLFY } & LFY-F & TCTCTCCCAAGAAGGGTTAT \\
\hline & LFY-R & GTAGTGTCGCATTTTAGGCT \\
\hline \multirow[t]{2}{*}{ RT-PCR for AtAP1 } & AP1-F & GACGTCAATACAAACTGGTCGA \\
\hline & AP1-R & GGAGATGGCTGATGAGAGAGC \\
\hline \multirow[t]{2}{*}{ RT-PCR for AtFLC } & FLC-F & GGCGATAACCTGGTCAAGAT \\
\hline & FLC-R & TAGTCACGGAGAGGGCAGTC \\
\hline \multirow[t]{2}{*}{ RT-PCR for AtUBQ10 } & AtUBQ-F & GATCTTTGCCGGAAAACAATTGGAGGATGG \\
\hline & AtUBQ-R & CGACTTGTCATTAGAAAGAAAGAGATAACAGG \\
\hline \multirow[t]{2}{*}{ RT-PCR for GmUBQ } & GmUBQ-F & CTCTGACAGGGAAGACCGTAAC \\
\hline & GMUBQ-R & ACGAGACCGTGCATAGCAA \\
\hline
\end{tabular}

transferred to destination vector by LR clonase (Invitrogen). The resultant vector was a binary vector in which GAL2 was driven by the CaMV $35 \mathrm{~S}$ promoter. It was transferred into Arabidopsis plants Ler with floral dipping approach mediated by Agrobacterium strain GV3101 90RK.

Phylogenetic Analysis

A phylogenetic analysis of protein sequences was carried out using the amino acid sequence alignment generated by CLUSTAL-W. A neighbor-joining tree was built using the software of MEGA version 3.1. Support for the tree was assessed using the bootstrap method with 1,000 bootstrap replicates. The numbers at each node represent the bootstrap support (percentage).

\section{Results}

Cloning the GAL2 Gene

We used the sequence of AGL11 (At4g09960) as a query in a tBLASTn sequence search (http://www.ncbi.nlm.nih.gov/). We detected a set of ESTs that showed high sequence similarity with AGL11 (The Gene Index Project, http:// compbio.dfci.harvard.edu/tgi/). Among them, AW705451 covered the 5' terminal sequence of a candidate gene. Based on the sequence of AW705451, specific RACE primers for the full-length candidate gene were designed: forward primer GAL2-F1 and reverse primer GAL2-R1 (Table 1). The reverse primer was part of an adapter primer that was employed as a reverse transcription primer for higher efficiency. Using the RACE approach, we cloned a MADS box gene, GAL2 (Glycine max Agamous Like 2). A BLAST analysis against the database of TAIR8 (http://www. arabidopsis.org/Blast) indicated that GAL2 is homologous to Arabidopsis AGL11 (Fig. 1a). Phylogenetic analysis (www. ncbi.nlm.nih.gov/blast) also suggests that GAL2 belonged to the dicot family of $A G L 11$ (Fig. 1b). GAL2 protein sequence had the highest similarity (95\% identity) to LjAGL11 and it had $75.2 \%$ identity with AtAGL11. GAL2 has relatively lower sequence similarity with the AGL11 homologs in monocots. Like other MADS box proteins, GAL2 has a MADS box (residues 3-57) and a K box (residues 74-177) at the $\mathrm{N}$ - terminus that are key to the MADS box functions. A bipartite nuclear localization signal (residues 9-26) was found within the MADS box region (Fig. 1a, http://myhits. isb-sib.ch/cgi-bin/motif_scan). 
Fig. 1 Alignments of protein sequences of soybean GAL2 and its homologs in Arabidopsis thaliana and Lotus japonicus. The red box denotes the MADS box, the pink box highlights the nuclear localization signal in the MADS box, and the green box shows the F box.

The species abbreviations are: At (Arabidopsis thaliana); CUM10 (Cucumis sativus); EgMADS1 (Elaeis guineensis); EgMADS1 (Eustoma grandiflorum); FBP7 (Petunia $\mathrm{x}$ hybrida); FBP11 (Petunia $\mathrm{x}$ hybrida); GhMADS-2 (Gossypium hirsutum); HoMADS1 (Hyacinthus orientalis); LjAGL11 (Lotus japonicus); LIMADS1 (Lilium longiflorum); LIMADS2 (Lilium longiflorum); LcMADS1 (Litchi chinensis); OsMADS13 (Oryza sativa); SlAGL11 (Solanum lycopersicum); VvMADS5 (Vitis vinifera); ZAG2 (Zea mays); and ZMMI (Zea mays)
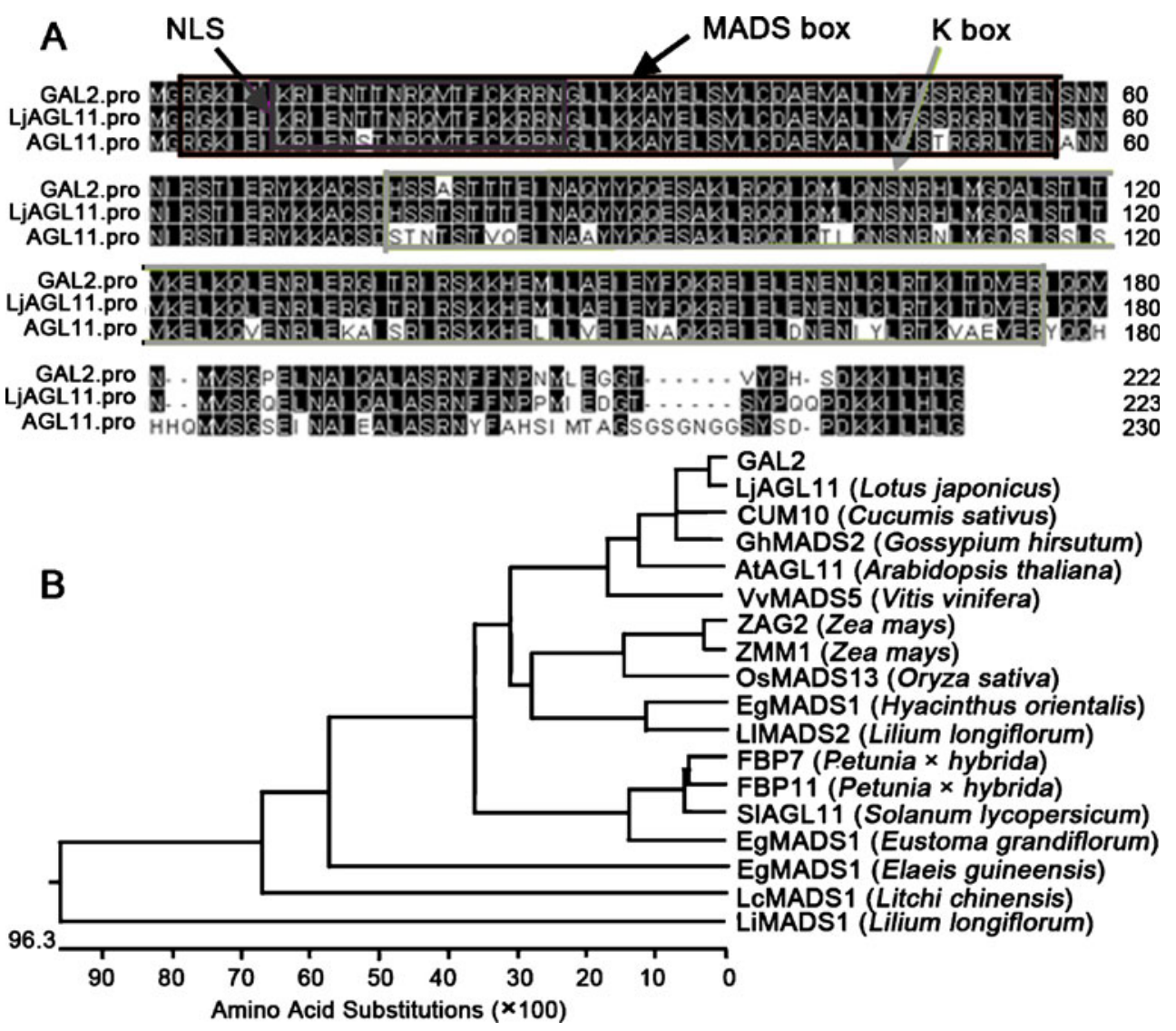

\section{GAL2 Promotes Flowering in Arabidopsis}

To study the function of GAL2 in plant development, we overexpressed GAL2 via the CaMV $35 \mathrm{~S}$ promoter in Arabidopsis plants. The transgenic plants were analyzed by RT-PCR (Fig. 2e and f) and quantitative PCR (Fig. 2g) to confirm the presence and expression level of the transferred gene. Three transgenic lines showed GAL2 expression. Transgenic plants expressing GAL2 flower earlier than the wild-type control; each line showed a different level of expression. It appears that the level of GAL2 expression correlates with the flowering time (Fig. 2d) and the total number of leaves (Fig. 2c). The acceleration of flowering in the transgenic plants expressing GAL2 was more pronounced in short-day conditions than in long-day conditions (Fig. 2a and b). These results suggest that the activity of GAL2 was partially dependent on photoperiod in Arabidopsis.

We next examined the level of expression of different flowering time genes in GAL2-overexpressing plants, including FLOWERING LOCUS T (FT), SUPPRESSOR OF OVEREXPRESSION OF CONSTANS (SOC1), CONSTANS (CO), APETALA1 (API), and LEAFY (LFY). Figure 3a shows that expressions of FT, SOC1, CO, APl, and $L F Y$ increased in transgenic lines, while the expression of flowering suppressor, FLC was repressed (Fig. 3). GmGAL2 overexpression in Arabidopsis induces flowering and leads to elevated levels of $C O$ and $F T$ mRNA. Expression of $S O C 1, A P 1$, and $L F Y$ is also increased, presumably as a consequence of higher $F T$ transcription, but it is also possible that overexpression in Arabidopsis of STK or GmGAL2 leads to artificial effects.

\section{GAL2 Affects the Development of Different Organs in Arabidopsis}

GAL2 also affected the development of different organs, just as OsMADS13 did (Favaro et al. 2002a). In transgenic plants, all the leaves are small and curl upwards, and this phenotype is much stronger in long-day conditions than in short-day condition (Figs. 2a and b, 4b and c). Flowers are smaller and shorter than that in the wild-type (Fig. 4d and e). In particular, the petals and sepals are shorter and do not cover the pistil completely, so that the filaments are exposed, but the style is longer than the wild-type (Fig. 4d). The number of seeds in each silique is reduced because the mature silique is shorter (Fig. 4g) than that of wild-type plants (Fig. 4f). Moreover, overexpression of GAL2 has some additional effects on plant development. As shown in Fig. $4 \mathrm{~g}$, the siliques in plants overexpressing GAL2 have persistent petals. However, carpel- and stamen-like organs, and ovule-like structures, were not found on any flower organs in the transgenic flowers. It is conceivable that GAL2 
Fig. 2 Overexpression of GAL2 enhances flowering in Arabidopsis. Plants overexpressing GAL2 flowered early in both long-day conditions (a) and short-day conditions (b), and had fewer leaves (c) and a shorter time of flowering from sowing (d). Transgenic plants were confirmed by RT-PCR (e and f; e shows the gel image and $\mathrm{F}$ shows figure plotted against the gel) and quantitative PCR (g). UBQ was used as the loading control for PCR
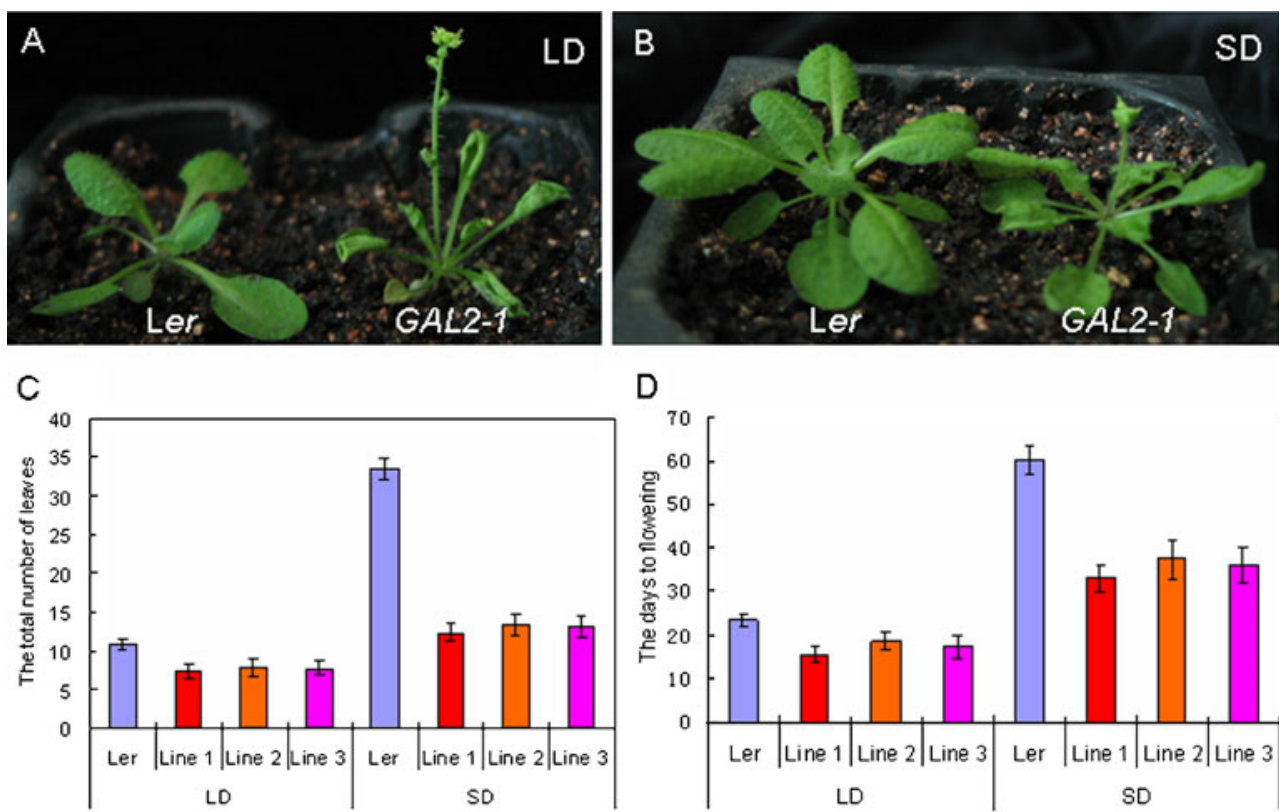

D

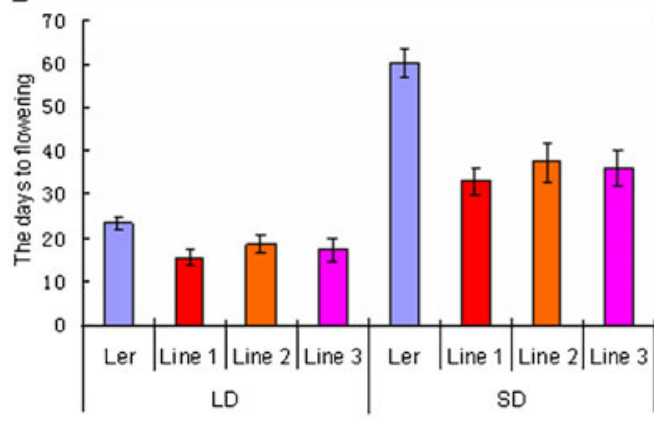

$\mathrm{E}$

$\mathrm{F}$

G

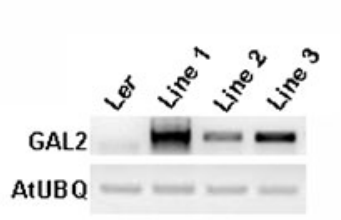

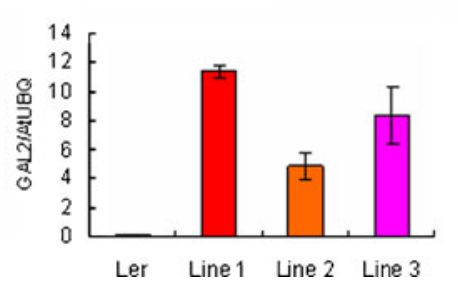

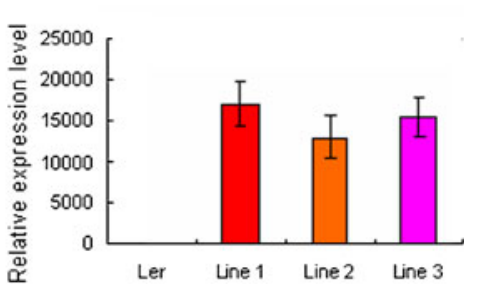

cloned from soybean might play additional roles in Arabidopsis development other than regulation of flowering time.

\section{GAL2 is Mainly Expressed in Flowers and Pods in Soybean}

The analysis of expression pattern of GAL2 in soybean showed that GAL2 is constitutively expressed in all organs and all developmental stages, but higher levels of expres- sion were found in flowers and pods than in vegetative organs (Fig. 5). This observation is consistent with its hypothesized role in organ development in soybean.

GmGAL2 expressed higher in SD than LD in soybean.

The analysis of expression pattern of GAL2 in soybean KN18 in short-day and long-day conditions showed GmGAL2 expressed higher in SD than LD in Soybean (Fig. 3b).
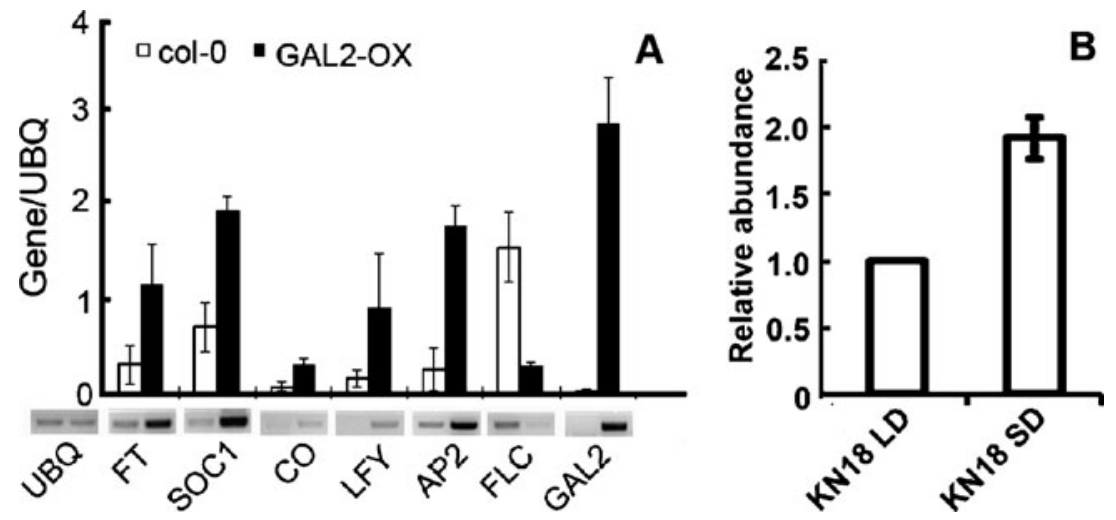

Fig. 3 The expression levels of flowering genes in transgenic Arabidopsis plants and the expression levels of GmGAL2 in soybean under long day and short day. a, Wild-type Arabidopsis seedlings and GAL2-overexpressing 10-day-old seedlings in long-day conditions
(16 h/8 h, light/dark) were harvested $3 \mathrm{~h}$ after light provision. The expression levels of Arabidopsis flowering genes were tested by RTPCR. b, GmGAL2 expressed higher in SD than LD in the flowers and mature pods of soybean KN18 plants 

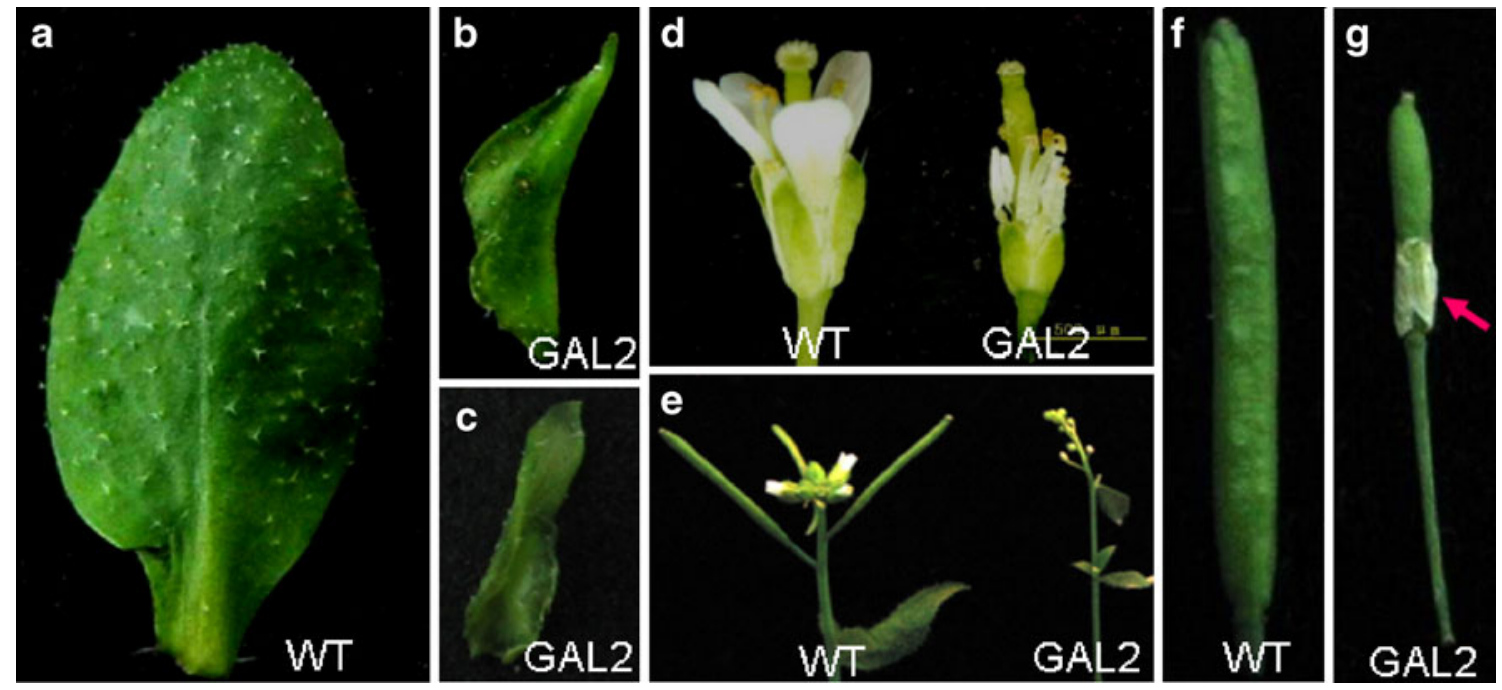

Fig. 4 The morphology of various organs in transgenic Arabidopsis. a, the leaf of the wild-type (WT); b, lateral view of a leaf of a transgenic plant; c, front view of a leaf of a transgenic plant; d, flowers of WT plants (left) and transgenic plants (right); e, The

inflorescence of WT (left) and transgenic plants (right); f, the silique of a WT plant; $\mathbf{g}$, the silique of a transgenic plant. An arrow shows the persistent petals on the silique

\section{Discussion}

We cloned a $S T K / A G L 11$ homolog from soybean, GAL2 (Glycine max Agamous Like 2). Its sequence shows high similarity to $A G L 11$ genes in many plants and it can be classed into the $A G L 11$ group of dicots. The sequence of GAL2 is most similar to an $A G L 11$ protein of a Legume plant (Lotus corniculatus, with $95 \%$ identity), while it only has $75.2 \%$ similarity to $A G L 11$ of a Cruciferae plant ( $A$. thaliana). The data suggests that $A G L 11$ might originate

from the same ancestor but has evolved independently in dicots, monocots, long-day plants, and short-day plants. Thus, AGL11 might have different functions between longday plants and short-day plants, although they share some conserved functions. The sequence of GAL2 shows typical characters of MADS box proteins, such as a highly conserved MADS box at the N-terminus, a nuclear localization signal in the MADS box, and a $\mathrm{K}$ box in the middle of the MADS box. These data suggest that GAL2 is a MADS box gene and a putative $S T K / A G L 11$ homolog in soybean.

Fig. 5 The expression levels in different organs or parts of soybean KN18.

The development stages are: I, fully expanded unifoliolate; II, fully expanded first trifoliolate; III, fully expanded second trifoliolate; IV, fully expanded third trifoliolate; V, plants in anthesis; and VI, plants setting pods. Upper panel shows the gel images

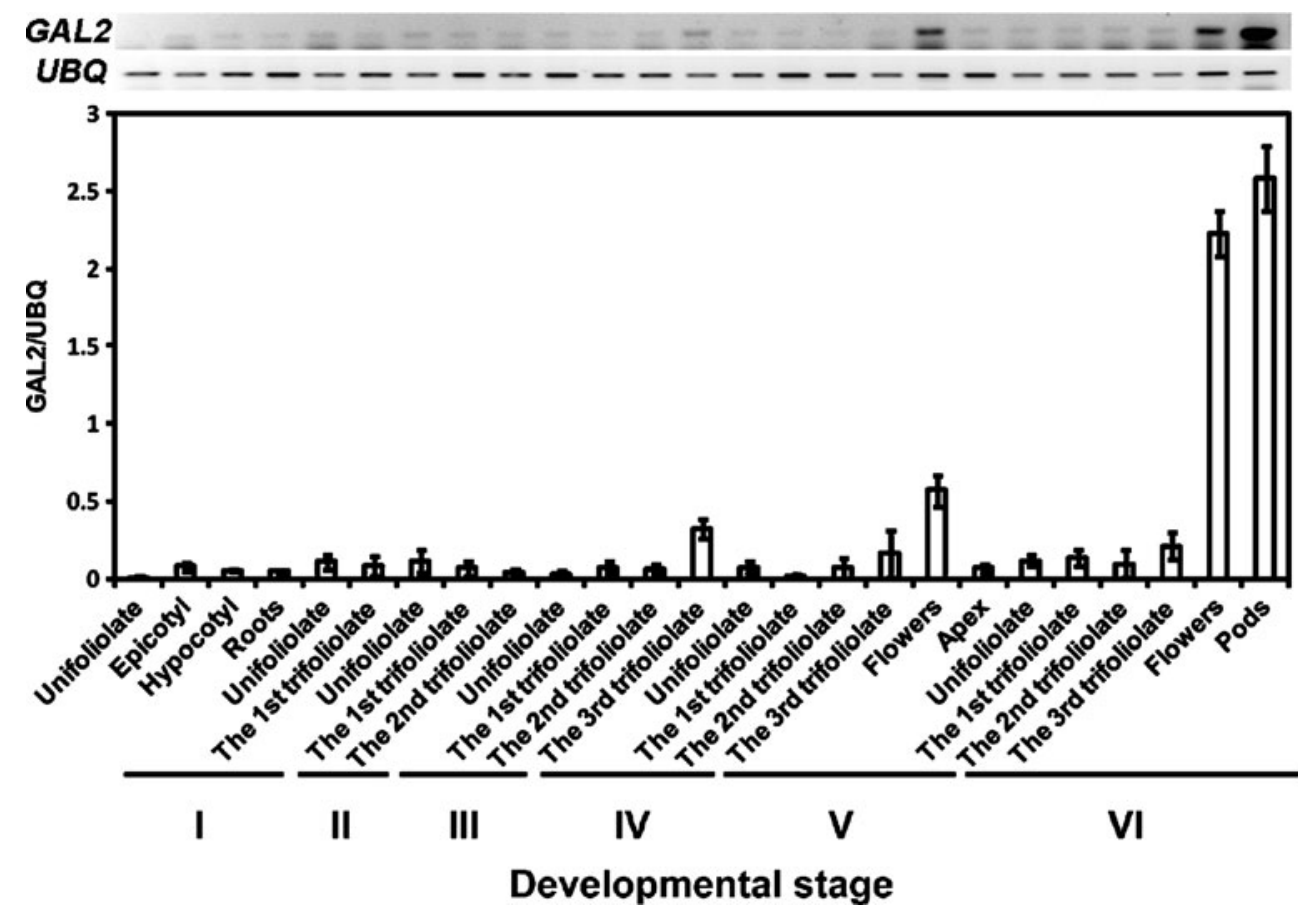


Like its homologs in other plants, ectopic expression of GAL2 affects Arabidopsis development, but its behavior is different to that of any other $A G L 11$ homolog. As does its homolog in lily, overexpression of GAL2 promotes flowering in Arabidopsis in both long-day conditions and shortday conditions; however, GAL2 might not be involved in the regulation of circadian clock, because ox-GmGAL2 does not seem to affect the circadian clock in Arabidopsis (data not shown). GAL2 does not affect the morphology of flower organs, including ovules and sepals, although it can cause smaller-sized flower organs. Soybean GAL2 has additional functions in the development of flower organs. Flowers and siliques are smaller than those of wild-type plants, and persistent petals are obvious on the siliques (Fig. 4). In soybean, GAL2 expresses at a higher level in flower organs and pods than in vegetative organs (Fig. 5). This suggests that GAL2 is mainly involved in regulation of flowers and pods, in addition to its possible function in all the stages of soybean development.

From the expression patterns of flowering genes, GAL2 participates in multiple pathways to enhance Arabidopsis flowering. In GAL2 transgenic Arabidopsis, flowering activators, such as $C O, F T, S O C 1, L F Y$, and $A P 1$, are upregulated, while the flowering repressors $(F L C)$ is downregulated.

Despite the low level of expression in vegetative stages, GAL2 might also function in the development of vegetative organs. The phenotype of the leaves (curly) of transgenic Arabidopsis supports that hypothesis (Fig. 4b, c). The effects of $A G L 11$ and its homologs on leaf development are dependent on species. The phenotype of curly leaves was observed in the bract leaves around flowers in Arabidopsis plants ectopically-expressing rice OSMADS13 (Favaro et al. 2002). The expression of AGL11 from Arabidopsis resulted in the presence of curved rosette leaves and bracts in transgenic Arabidopsis plants (Favaro et al. 2002). All the leaves have curly phenotype in plants overexpressing GAL2 (Fig. 2a and b). Therefore, GAL2's function in leaf development is not the same as that of OSMADS13, even though both rice and soybean are short-day plants. The effect of GAL2 on leaf development might be in a photoperiod-dependent manner because the long-day condition enhances GAL2 function (Fig. 2a and b).

In summary, GAL2 is a homolog of A. thaliana AGL11 in soybean. It has similar, but not identical, functions on plant development compared with its homolog in other plants.

Acknowledgments This work was supported in part by the Chinese national "863" Program (2006AA10Z107), the Chinese National Science Foundation (30671245), and the Core Research Budget of the Nonprofit Governmental Research Institution (2060302-2-09). Major Science and Technology Projects 2008ZX08010-004 and 2009ZX08004-010B.
Open Access This article is distributed under the terms of the Creative Commons Attribution Noncommercial License which permits any noncommercial use, distribution, and reproduction in any medium, provided the original author(s) and source are credited.

\section{References}

Alvarez-Buylla ER, Liljegren SJ, Pelaz S, Gold SE, Burgeff C, Ditta GS, Vergara-Silva F, Yanofsky MF (2000) MADS-box gene evolution beyond flowers: expression in pollen, endosperm, guard cells, roots and trichomes. Plant J 24:457-466

Battaglia R, Brambilla V, Colombo L, Stuitje AR, Kater MM (2006) Functional analysis of MADS-box genes controlling ovule development in Arabidopsis using the ethanol-inducible alc gene-expression system. Mech Dev 123(4):267-276. doi:10.1016/j.mod.2006.01.002

Bodt De S, Raes J, Van de Peer Y, Theissen G (2003) And then there were many: MADS goes genomic. Trends Plant Sci 8:475-483. doi:10.1016/j.tplants.2003.09.006

Colombo L, Franken J, Koetje E, Went van J, Dons HJ, Angenent GC, Tunen van AJ (1995) The petunia MADS box gene FBP11 determines ovule identity. Plant Cell 7:1859-1868

Colombo L, Franken J, Van der Krol AR, Wittich PE, Dons HJ, Angenent GC (1997) Downregulation of ovule-specific MADS box genes from petunia results in maternally controlled defects in seed development. Plant Cell 9:703-715

El-Din El-Assal S, Alonso-Blanco C, Peeters AJ, Wagemaker C, Weller JL, Koornneef M (2003) The role of cryptochrome 2 in flowering in Arabidopsis. Plant Physiol 133:1504-1516. doi:10.1104/pp.103.029819

Favaro R, Immink RG, Ferioli V, Bernasconi B, Byzova M, Angenent GC, Kater M, Colombo L (2002) Ovule-specific MADS-box proteins have conserved protein-protein interactions in monocot and dicot plants. Mol Genet Genomics 268:152-159. doi:10.1007/s00438-002-0746-6

Favaro R, Kooiker M, Battaglia R, Franzi S, Colombo L, Kater M (2006) AGL11 an ovule specific gene in Arabidopsis thaliana functional analysis. 13th International Conference on Arabidopsis Research

Foo E, Ross JJ, Davies NW, Reid JB, Weller JL (2006) A role for ethylene in the phytochrome-mediated control of vegetative development. Plant J 46:911-921. doi:10.1111/j.1365-313X.2006. 02754.x

Gregis V, Sessa A, Dorca-Fornell C, Kater MM (2009) The Arabidopsis floral meristem identity genes AP1, AGL24 and SVP directly repress class B and C floral homeotic genes. Plant J 60(4):626-637

Guo H, Yang H, Mockler TC, Lin C (1998) Regulation of flowering time by Arabidopsis photoreceptors. Science 279:1360-1363. doi:10.1126/science. 279.5355 .1360

Hepworth SR, Valverde Ravenscroft FD, Mouradov A, Coupland G (2002) Antagonistic regulation of flowering-time gene SOC1 by CONSTANS and FLC via separate promoter motifs. EMBO J 21:4327-4337. doi:10.1093/emboj/cdf432

Irish VF (2003) The evolution of floral homeotic gene function. Bioessays 25:637-646. doi:10.1002/bies.10292

Kater MM, Dreni L, Colombo L (2006) Functional conservation of MADS-box factors controlling floral organ identity in rice and Arabidopsis. J Exp Bot 57:3433-3444. doi:10.1093/jxb/ er1097

Kim S, Kim SR, An CS, Hong YN, Lee KW (2001) Constitutive expression of rice MADS box gene using seed explants in hot pepper (Capsicum annuum L.). Mol Cells 12:221-226 
Lee S, Kim J, Han JJ, Han MJ, An G (2004) Functional analyses of the flowering time gene OsMADS50, the putative SUPPRESSOR OF OVEREXPRESSION OF CO 1/AGAMOUS-LIKE 20 (SOC1/AGL20) ortholog in rice. Plant J 38:754-764

Lopez-Dee ZP, Wittich P, Enrico Pe M, Rigola D, Del Buono I, Gorla MS, Kater MM, Colombo L (1999) OsMADS13, a novel rice MADS-box gene expressed during ovule development. Dev Genet 25:237-244

Messenguy F, Dubois E (2003) Role of MADS box proteins and their cofactors in combinatorial control of gene expression and cell development. Gene 316:1-21. doi:10.1016/S0378-1119(03) 00747-9

Moon J, Suh SS, Lee H, Choi KR, Hong CB, Paek NC, Kim SG, Lee I (2003) The SOC1 MADS-box gene integrates vernalization and gibberellin signals for flowering in Arabidopsis. Plant J 35:613623. doi:10.1046/j.1365-313X.2003.01833.x

Parenicova L, Folter de S, Kieffer M, Horner DS, Favalli C, Busscher $\mathrm{J}$, Cook HE, Ingram RM, Kater MM, Davies B, Angenent GC, Colombo L (2003) Molecular and phylogenetic analyses of the complete MADS-box transcription factor family in Arabidopsis: new openings to the MADS world. Plant Cell 15:1538-1551. doi: $10.1105 /$ tpc. 011544

Pinyopich A, Ditta GS, Savidge B, Liljegren SJ, Baumann E, Wisman E, Yanofsky MF (2003) Assessing the redundancy of MADS-box genes during carpel and ovule development. Nature 424:85-88. doi:10.1038/nature 01741

Poduska B, Humphrey T, Redweik A, Grbic V (2003) The synergistic activation of FLOWERING LOCUS $\mathrm{C}$ by FRIGIDA and a new flowering gene AERIAL ROSETTE 1 underlies a novel morphology in Arabidopsis. Genetics 163:1457-1465. doi:10.1038/nature 01741

Rijpkema AS, Gerats T, Vandenbussche M (2007) Evolutionary complexity of MADS complexes. Curr Opin Plant Biol 10:3238. doi:10.1016/j.pbi.2006.11.010

Robles P, Pelaz S (2005) Flower and fruit development in Arabidopsis thaliana. Int J Dev Biol 49:33-43. doi:10.1387/ijdb.052020pr

Rounsley SD, Ditta GS, Yanofsky MF (1995) Diverse roles for MADS box genes in Arabidopsis development. Plant Cell 7:1259-1269
Rouse DT, Sheldon CC, Bagnall DJ, Peacock WJ, Dennis ES (2002) FLC, a repressor of flowering, is regulated by genes in different inductive pathways. Plant 29:183-191. doi:10.1046/j.09607412.2001.01210.x

Saedler H, Huijser P (1993) Molecular biology of flower development in Antirrhinum majus (snapdragon). Gene 135:239-243. doi:10.1016/0378-1119(93)90071-A

Samach A, Onouchi H, Gold SE, Ditta GS, Schwarz-Sommer Z, Yanofsky MF, Coupland G (2000) Distinct roles of CONSTANS target genes in reproductive development of Arabidopsis. Science 288:1613-1616. doi:10.1126/science.288.5471.1613

Skipper M, Johansen LB, Pedersen KB, Frederiksen S, Johansen BB (2006) Cloning and transcription analysis of an AGAMOUS- and SEEDSTICK ortholog in the orchid Dendrobium thyrsiflorum (Reichb. f.). Gene 366:266-274. doi:10.1016/j.gene.2005.08.014

Sheldon CC, Burn JE, Perez PP, Metzger J, Edwards JA, Peacock WJ, Dennis ES (1999) The FLF MADS box gene: a repressor of flowering in Arabidopsis regulated by vernalization and methylation. Plant Cell 11:445-458

Swarup K, Alonso-Blanco C, Lynn JR, Michaels SD, Amasino RM, Koornneef M, Millar AJ (1999) Natural allelic variation identifies new genes in the Arabidopsis circadian system. Plant J 20:67-77

Tapia-Lopez R, Garcia-Ponce B, Dubrovsky JG, Garay-Arroyo A, Perez-Ruiz RV, Kim SH, Acevedo F, Pelaz S, Alvarez-Buylla ER (2008) An AGAMOUS-related MADS-box gene, XAL1 (AGL12), regulates root meristem cell proliferation and flowering transition in Arabidopsis. Plant Physiol 146:1182-1192. doi:10.1104/pp.107.108647

Tzeng TY, Hsiao CC, Chi PJ, Yang CH (2003) Two lily SEPALLATAlike genes cause different effects on floral formation and floral transition in Arabidopsis. Plant Physiol 133:1091-1101. doi:10. 1104/pp.103.026997

Zhang QZ, Li HY, Li R, Hu RB, Fan CM, Wang ZH, Liu X, Fu YF, Lin $C$ (2008) Association of the circadian rhythmic expression of GmCRY1a with a latitudinal cline in photoperiodic flowering of soybean. PNAS 105(51):21028-21033. doi:10.1073/ pnas. 0810585105 